\title{
LAMA RESIDUAL DE USINAS DE CONCRETO: CARACTERÍSTICAS E APLICAÇÕES NA CONFECÇÃO DE BLOCOS
}

\section{Residual sludge from concrete plants: characteristics and applications in the confection of blocks}

Walter Batista Bonfim', Victor Baldin², Ruvier Rodrigues Pereira ${ }^{3}$, Heber Martins de Paula ${ }^{4}$ Recebido em 24 de janeiro de 2017; recebido para revisão em 06 de março de 2017; aceito em 03 de abril de 2017; disponível on-line em 04 de abril de 2017.

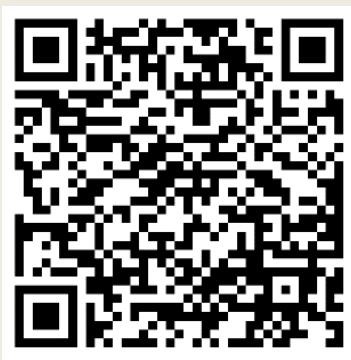

PALAVRAS CHAVE:

Lama residual de concreto;

Blocos de concreto;

Resíduos;

Usinas dosadoras de concreto;

Mapeamento sistêmico.

\section{KEYWORDS:}

Concrete sludge waste;

Concrete blocks;

Wastes;

Concrete batching plants;

Mapping study.

\section{* Contato com os autores:}

'e-mail: walter-bonfim@hotmail.com (W. B. Bonfim)

Engenheiro Civil, graduado pela Universidade Federal de Goiás - UFG.

2e-mail: vbaldin23@gmail.com (V. Baldin)

Engenheiro Civil, graduado pela Universidade Federal de Goiás - UFG.

${ }^{3}$ e-mail: ruvierrodrigues@hotmail.com (R. R. Pereira)

Mestrando em Modelagem e Otimização da Universidade Federal de Goiás - UFG.

${ }^{4}$ e-mail: heberdepaula@hotmail.com ( H. M. de Paula)

Professor, Doutor, na Universidade Federal de Goiás - UFG.
ABSTRACT: The production of concrete in dosing plants is growing and, with this, there is also ase of inherent residues of the production process. The objective of this paper is to (he fosired slope, through the in the use of residues in that there is a great variety of residues applied in masonry, being the most studied the use of fly ash and construction and demolition residues. On the other hand, there are still few studies that use residual sludge in concrete products, mainly for the production of masonry. In this context, it is understood that there is no consensus regarding the best use of concrete sludge Finally, this work points to a residue that has not yet been studied, but with possible applications in new research. Its characteristics such as the presence of $\mathrm{SiO}_{2}$ and $\mathrm{CaO}$ indicate a potential for use as a binder, which can lead to a reduction in the consumption of cement. 


\section{INTRODUÇÃO}

O segmento das indústrias de concreto se fortaleceu na última década, visto que, enquanto o consumo de concreto no Brasil obteve um aumento de $80 \%$, o segmento das dosadoras alcançou um crescimento de $180 \%$ no mesmo período, com uma produção aproximada de 51 milhões de $\mathrm{m}^{3}$ em 2012 (ABCP, 2013). No entanto, o crescimento da produção representa também aumento de resíduos inerentes do processo produtivo.

Pesquisas realizadas pela Associação Brasileira de Serviços de Concretagem - ABESC, mostram que, de toda a quantia produzida de concreto no país, cerca de $2 \%$ é desperdiçada, voltando às concreteiras para descarte (VIEIRA; FIGUEIREDO, 2013). No entanto, Correia et al. (2009) apresentam que a otimização de processos de fabricação e a adoção de "tecnologias limpas" têm se mostrado capaz de minimizar a geração de resíduos e mesmo assim, produzir produtos iguais ou melhores com menor consumo de energia e matéria prima.

A produção de concreto pré-misturado em uma unidade de dosagem envolve a pesagem exata da quantidade necessária de cada material constituinte, seguido pela mistura em caminhões betoneira ou misturadores estáticos. Assim como qualquer processo produtivo, a produção de concreto gera alguns resíduos, sendo as principais fontes: o concreto devolvido à central, a lavagem dos caminhões após cada dia de trabalho e a lavagem do pátio (SEALEY; PHILLIPS; HILL, 2001).

O concreto devolvido é usualmente utilizado para melhorias dentro da empresa ou disposto em baias de secagem para posterior disposição em aterros sanitários. Já a água utilizada para a lavagem dos caminhões e do pátio forma a chamada água residuária de concreto. Para a melhora da qualidade deste efluente, a água utilizada é direcionada para tanques de sedimentação, nos quais, através da ação da gravidade, haverá a deposição dos sólidos, dando origem à lama residual de concreto. Periodicamente, este resíduo sólido deverá ser dragado dos tanques e destinado a baias de secagem, para posterior disposição em aterros sanitários (ERMCO, 2006).

A reciclagem pode ser uma solução viável a ser utilizada pelo setor industrial, visto que Tam (2008) afirma que este tipo de iniciativa pode gerar benefícios ambientais e econômicos como: diminuição do volume de materiais lançados em aterros, redução na demanda por recursos naturais e redução de custos de produção e de transporte dos resíduos até os aterros sanitários. A indústria do concreto é particularmente importante, não só pelo seu alto consumo de recursos naturais e energia, mas também pela sua capacidade de absorver resíduos e subprodutos industriais (ALMEIDA; BRANCO; SANTOS, 2007).

Kou, Zhan e Poon (2012a) destacam que, quando comparado com outros resíduos como os de construção e demolição, há pouca informação disponível a respeito da reciclagem ou reutilização da lama residual do concreto. Tal situação abre oportunidade para novos autores, que devem contemplar o panorama dessa vertente de pesquisa.

\section{OBJETIVO}

Portanto, o objetivo deste artigo é verificar o panorama das pesquisas relacionadas com a lama residual de concreto com ênfase na utilização em blocos de concreto, apresentando um estudo sistêmico acerca do que vem sendo publicado para tal vertente.

\section{METODOLOGIA}

A metodologia utilizada para a revisão de literatura foi realizada conforme o método proposto por Bailey et al. (2007) e Petersen et al. (2008). Esta metodologia, chamada mapping study (mapeamento sistêmico), consiste em utilizar de operadores lógicos (strings) e palavras ou expressões chaves para selecionar artigos cadastrados em bases de dados.

Foi considerada somente a base de dados presente no Portal de Periódicos da Coordenação de Aperfeiçoamento de Pessoal de Nível Superior CAPES, acessados pelo sistema da Universidade 
Federal de Goiás, com os seguintes operadores lógicos e expressões chaves: (a) "Concrete blocks" and Recycled; (b) "Concrete Masonry Units"; (c) "Fresh concrete waste" e (d) "Concrete sludge". As expressões utilizadas foram escolhidas de forma a abranger tanto estudos relacionados com a utilização de resíduos em alvenarias de concreto (a e b), quanto com enfoque na lama residual de concreto (c e d).

Após a busca inicial, os artigos repetidos dentro da mesma busca foram retirados e aplicado o filtro quanto ao tipo de publicação (artigos revisados por pares). Feito isso, foi iniciada a leitura e análise de títulos e resumos aderentes, para selecionar apenas aqueles estudos que se relacionam diretamente com o objeto de estudo (PAULA; ILHA, 2016).

A etapa seguinte consistiu em destacar os artigos repetidos entre as buscas, com o intuito de não contabilizar ocorrências duplicadas. Por fim, foi iniciada a etapa chamada de snowball sampling, que consistiu em analisar as referências utilizadas pelos artigos selecionados, buscando possíveis estudos que não foram detectados nas buscas realizadas.

Além dos artigos obtidos com o mapeamento sistêmico foram utilizados também livros, normas e outros artigos, nacionais e internacionais, relevantes ao estudo, conforme proposto por Paula e Ilha (2016).

\section{RESULTADOS}

Realizada as etapas propostas para o mapeamento sistemático, foram obtidos os resultados parciais e totais apresentados na Tabela 1. Como descrito na metodologia, as buscas realizadas pertencem a dois tópicos principais: utilização de resíduos em alvenarias de concreto e estudos relacionados com a lama residual de concreto.

Buscando identificar a importância destes dois temas ao longo dos anos, foi elaborada a Figura 1, identificando a evolução de publicações em função das expressões-chave pertencentes a cada tópico. Percebe-se, então, um aumento no número de publicações a partir do período de 2001-2006, em ambos os tópicos em análise. No entanto, as pesquisas realizadas não são suficientes para analisar e discutir os principais temas relacionados à utilização de resíduos em alvenarias de concreto e sobre a lama residual de concreto, haja vista a grande variedade de resíduos passíveis de serem utilizados na confecção de alvenarias, além das diversas formas de aplicação dos mesmos, conforme será abordado no item 4.1 deste artigo. Tem-se também, a respeito da lama residual de concreto, que o tema ainda está em fase inicial de estudos, podendo ter diversas aplicações em várias áreas, conforme será abordado no item 4.2.

TABELA 1: Resumo dos resultados obtidos no mapeamento.

\begin{tabular}{|c|c|c|c|c|}
\hline \multirow{5}{*}{ Critérios utilizados } & \multicolumn{4}{|c|}{ Objeto de estudo } \\
\hline & \multicolumn{2}{|c|}{ Resíduos em alvenarias de concreto } & \multicolumn{2}{|c|}{ Lama residual de concreto } \\
\hline & \multicolumn{4}{|c|}{$\begin{array}{l}\text { Expressões-chave } \\
\end{array}$} \\
\hline & $\begin{array}{l}\text { "Concrete blocks" } \\
\text { and Recycled }\end{array}$ & $\begin{array}{l}\text { "Concrete } \\
\text { masonry units" }\end{array}$ & $\begin{array}{l}\text { "Fresh concrete } \\
\text { waste" }\end{array}$ & $\begin{array}{l}\text { "Concrete } \\
\text { sludge" }\end{array}$ \\
\hline & \multicolumn{4}{|c|}{ Número de artigos } \\
\hline $\begin{array}{l}\text { Número inicial de artigos sem } \\
\text { repetições dentro da mesma busca }\end{array}$ & 93 & 242 & 18 & 46 \\
\hline $\begin{array}{l}\text { Artigos selecionados após análise } \\
\text { de aderência de títulos }\end{array}$ & 74 & 138 & 15 & 21 \\
\hline $\begin{array}{l}\text { Artigos selecionados após leitura } \\
\text { dos resumos }\end{array}$ & 16 & 21 & 11 & 10 \\
\hline Artigos repetidos entre as buscas & \multicolumn{4}{|c|}{4} \\
\hline Snowball sampling & \multicolumn{4}{|c|}{18} \\
\hline Total & \multicolumn{4}{|c|}{72} \\
\hline
\end{tabular}




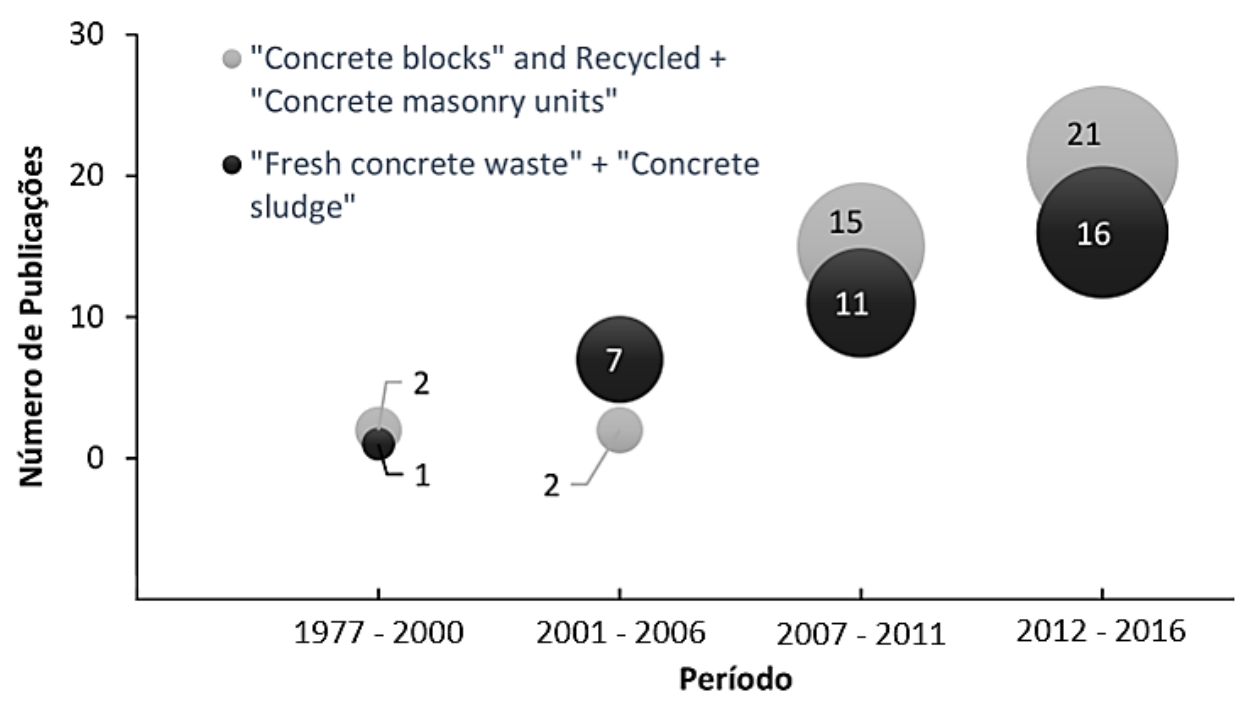

FIGURA 1: Evolução do número de artigos publicados em função das expressões-chave utilizadas no mapeamento.

FONTE: Autoria Própria.

Através da avaliação dos periódicos nos quais os artigos selecionados foram publicados (Tabela 2), foi possível verificar que o periódico "Construction and Building Materials" obteve um número expressivo de artigos publicados em ambos os temas estudados. Este periódico alcançou 57\% dos artigos com enfoque na utilização de resíduos em alvenarias de concreto e $20 \%$ dos artigos com estudos relacionados com a lama residual de concreto, demonstrando, assim, grande potencial para pesquisas relacionadas com o aproveitamento da lama residual em alvenarias de concreto.
Com o intuito de avaliar a produção científica mundial nos tópicos estudados, os artigos foram classificados de acordo com o país em que foram realizados (Figura 2). Analisando os dados apresentados, foi identificado que a China e a Turquia são os dois grandes centros de pesquisas no tópico de alvenarias de concreto com resíduos. Já avaliando pesquisas relacionadas com a lama residual de concreto, é possível destacar a produção brasileira, atrás apenas da produção japonesa. As instituições brasileiras com pesquisas nessa área são as Universidades de Santa Catarina e de São Paulo.

TABELA 2: Principais periódicos com artigos nos temas estudados.

\begin{tabular}{|c|c|c|c|c|c|}
\hline \multirow[b]{2}{*}{ Periódico } & \multicolumn{5}{|c|}{ Número de artigos publicados } \\
\hline & $\begin{array}{l}\text { "Concrete } \\
\text { blocks" and } \\
\text { Recycled }\end{array}$ & $\begin{array}{c}\text { "Concrete } \\
\text { masonry } \\
\text { units" }\end{array}$ & $\begin{array}{l}\text { "Fresh concrete } \\
\text { waste" }\end{array}$ & $\begin{array}{l}\text { "Concrete } \\
\text { sludge" }\end{array}$ & Total \\
\hline Building and Environment & - & 3 & - & - & 3 \\
\hline Cement and Concrete Composites & 1 & - & 2 & 1 & 4 \\
\hline Cement and Concrete Research & - & - & 1 & 2 & 3 \\
\hline Construction and Building Materials & 10 & 10 & 5 & 2 & 27 \\
\hline Journal of Cleaner Production & 2 & 1 & - & - & 3 \\
\hline $\begin{array}{l}\text { Journal of Materials in Civil } \\
\text { Engineering }\end{array}$ & 1 & - & 1 & 1 & 3 \\
\hline Waste Management & 2 & 1 & 4 & 1 & 8 \\
\hline Total & 16 & 15 & 13 & 7 & 51 \\
\hline
\end{tabular}




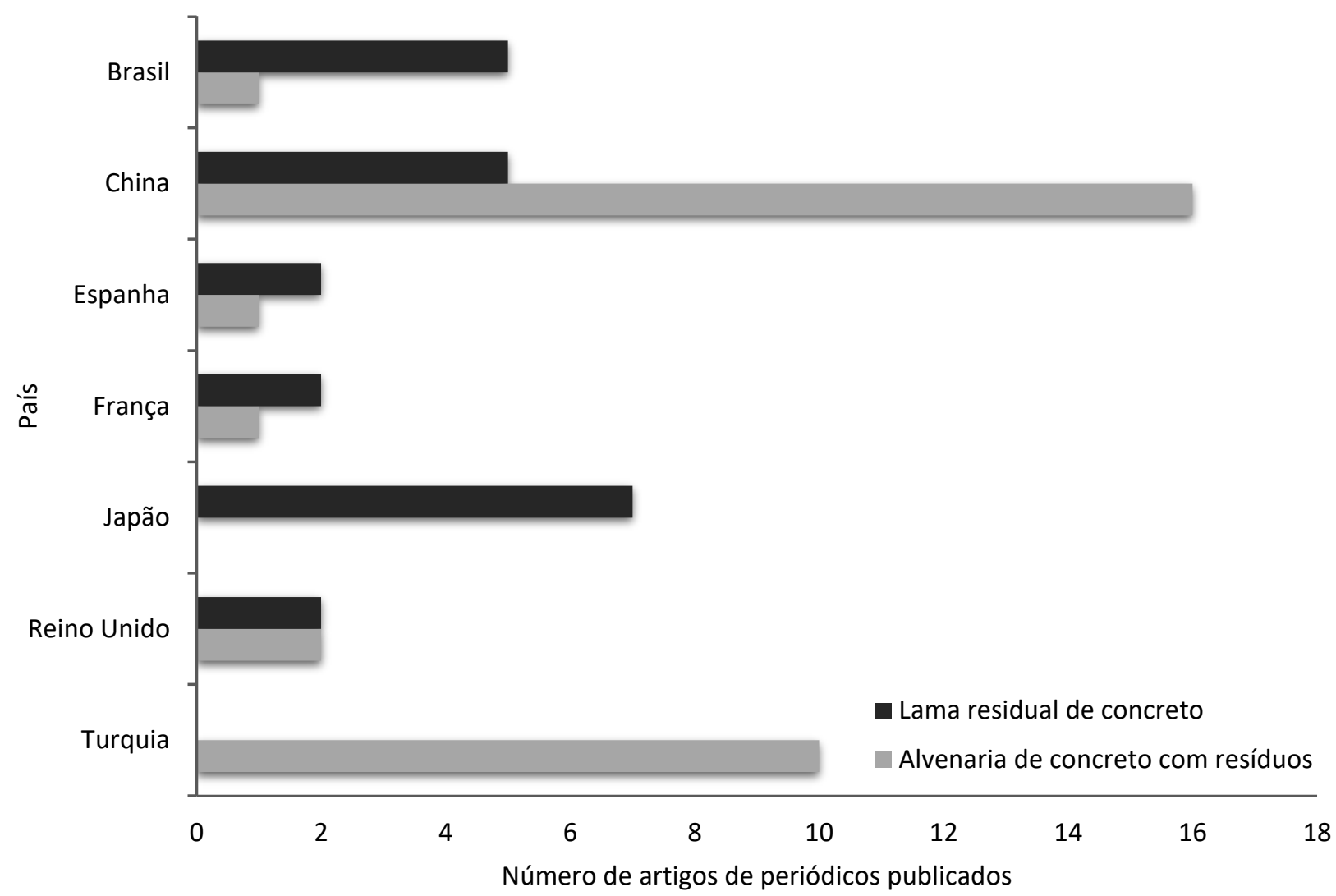

FIGURA 2: Principais países com publicações de artigos de periódicos contidos no mapeamento realizado.

FONTE: Autoria Própria.

\subsection{RESÍDUOS UTILIZADOS EM ALVENARIAS DE CONCRETO}

Após leitura dos artigos selecionados dentro do tópico "utilização de resíduos em alvenarias de concreto", foi verificado que o aproveitamento de resíduos para a confecção de alvenarias tem ocorrido de três formas: substituição total ou parcial do cimento Portland, substituição total ou parcial de agregados miúdos ou substituição total ou parcial de agregados graúdos.

Dentre os materiais utilizados como elemento de substituição do cimento Portland, as cinzas volantes obtiveram maior número de estudos (Figura 3). É possível atribuir este resultado ao fato de que, quando comparadas com os demais resíduos presentes, o uso de cinzas volantes no concreto é relativamente comum na construção civil, sendo inclusive normatizado pela NBR 12653 (ABNT, 2014).

Já com relação aos agregados, os resíduos de construção e demolição tiveram maior destaque tanto como substituto de agregados miúdos (Figura 4), quanto de agregados graúdos (Figura 5). Já em relação a utilização da lama residual de concreto, tem-se que, em se tratando de agregado, ela vem sendo aplicada apenas como substituição do agregado miúdo, porém ainda com poucos estudos. Os resultados obtidos vão ao encontro do que diz em Kou, Zhan e Poon (2012a), quando afirmam que as pesquisas relacionadas com a reciclagem de resíduos de construção e demolição têm sido conduzidas extensivamente nas últimas décadas e que tem pouca informação disponível acerca da lama residual de concreto. 


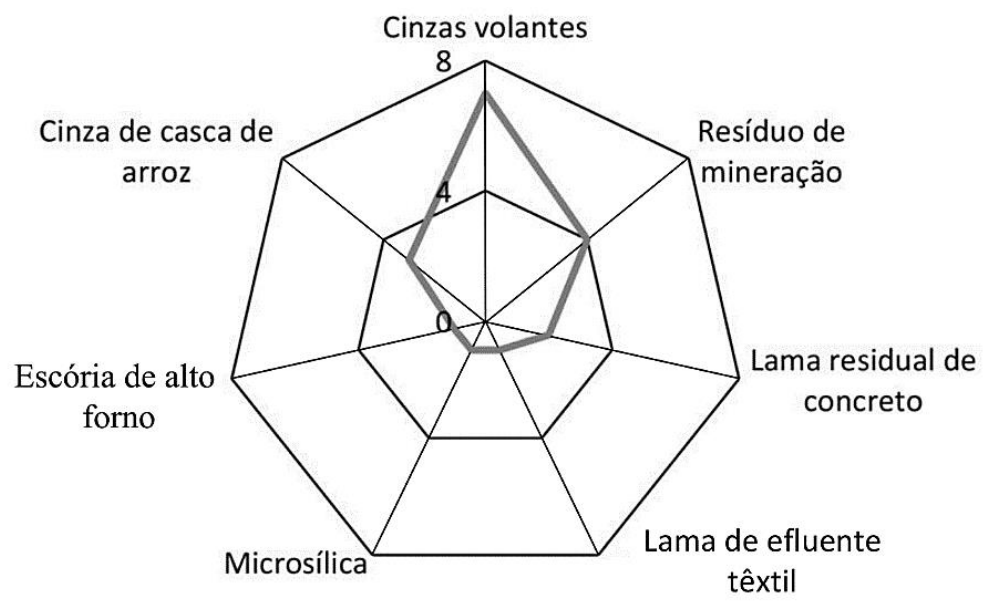

FIGURA 3: Resíduos utilizados como elemento de substituição do cimento Portland em alvenarias de concreto. FONTE: Autoria Própria.

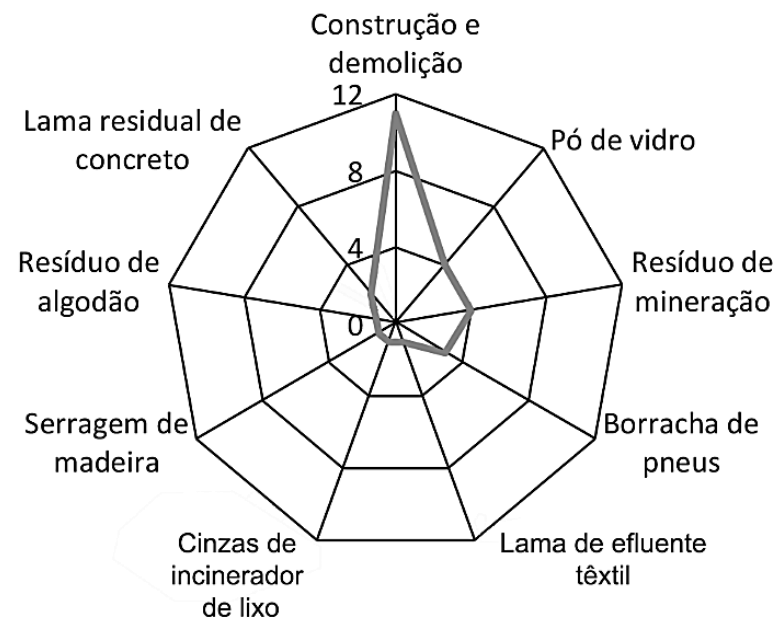

FIGURA 4: Resíduos utilizados como elemento de substituição de agregados miúdos em alvenarias de concreto. FONTE: Autoria Própria.

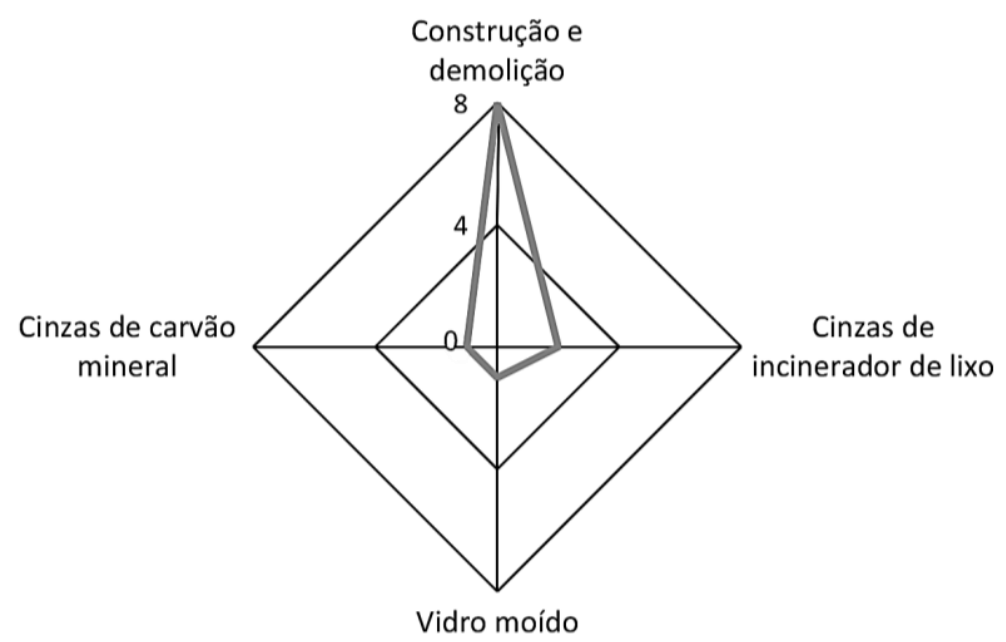

FIGURA 5: Resíduos utilizados como elemento de substituição de agregados graúdos em alvenarias de concreto. FONTE: Autoria Própria.

A variedade de resíduos encontrados neste mapeamento demonstra o potencial que os blocos de concreto possuem para absorver resíduos de diversas origens. Nesse contexto, os principais autores encontrados com pesquisas relacionadas a esse tópico estão apresentados na Tabela 3. Como destaque, pode-se citar o pesquisador Paki Turgut, que possui como enfoque principal a utilização de resíduos de mineração como substituto do Cimento Portland e de agregados miúdos. 
TABELA 3: Principais pesquisadores dentro do tópico "utilização de resíduos em alvenarias de concreto".

\begin{tabular}{ccc} 
Pesquisador* & Número de publicações & Período \\
\hline Demirdag, S. & 2 & 2008 (2) \\
Kou, S. C. & 2 & 2012 \\
Lee, G. & 2 & 2011 e 2013 \\
Poon, C. S. & 2 & 2002 e 2009 \\
Turgut, P. & 6 & 2007,2008 (2), 2010, 2012, 2013 \\
Wang, L. & 2 & 2015 (2) \\
Xiao, Z. & 2 & 2011 e 2013 \\
Zhan, B. J. & 2 & 2013 e 2015
\end{tabular}

\subsection{LAMA RESIDUAL DE CONCRETO}

A indústria da construção foi reconhecida não só como uma das atividades mais importantes para o desenvolvimento socioeconômico, mas também como uma das principais causadoras de impactos ambientais (CORREIA et al., 2009). Nesse contexto, é de suma importância a adoção de técnicas inovadoras de reciclagem e reutilização de resíduos de cimento e concreto para a promoção da proteção ambiental e com o objetivo de alcançar o desenvolvimento sustentável na indústria do concreto (XUAN et al., 2016a).

Através de um amplo estudo envolvendo 109 concreteiras de diversos estados brasileiros, Vieira e Figueiredo (2013) identificaram que as perdas de concreto durante a sua produção em usinas são dadas fundamentalmente dentro do seu processo produtivo (materiais que caem no pátio, concretos com abatimento inadequado e matériaprima utilizada no controle tecnológico) ou durante sua fase de entrega, através do concreto devolvido às centrais dosadoras e do material aderido aos balões dos caminhões betoneira (lastro). Os dados encontrados pelos autores vão ao encontro do estudo desenvolvido por Sealey, Phillips e Hill (2001) no Reino Unido, onde foram identificadas que a devolução de concreto às usinas e a lavagem de pátios e caminhões são as principais fontes de resíduos dentro de centrais dosadoras de concreto.

Uma iniciativa relativamente comum nas concreteiras é a utilização das sobras de concreto para realização de melhorias na própria empresa (concretagem do pavimento, confecção de blocos para separação de baias etc.); no entanto, este tipo de ação é limitada, visto que as melhorias na central são finitas (VIEIRA; FIGUEIREDO, 2013). A lavagem de pátios e caminhões gera a chamada água residuária de concreto que, em função de suas características (alta alcalinidade, $\mathrm{pH}$ elevado e alto teor de sólidos), deve passar por um tratamento antes de sua descarga para um sistema público ou, até mesmo, para algum possível reuso (PAULA; ILHA, 2014).

Para a melhora da qualidade da água residuária do concreto, Tsimas e Zervaki (2011) e Sealey, Phillips e Hill (2001) apresentam métodos semelhantes (Figura 6). Basicamente, o sistema consiste em direcionar a água residuária à um primeiro tanque, para que ocorra a deposição dos sólidos em seu fundo, e o excesso de água transborda para outros dois tanques. A diferença se encontra a partir do terceiro tanque. Enquanto Sealey, Phillips e Hill (2001) sugerem que a água decantada seja reutilizada para lavagem do pátio e dos caminhões betoneira, Tsimas e Zervaki (2011) propõem a correção de seu $\mathrm{pH}$ para aproximadamente 7 (sete) e sua dissolução em água potável ou subterrânea em proporções pequenas ( 0 a $20 \%$ ), para sua reutilização na produção de concreto. 


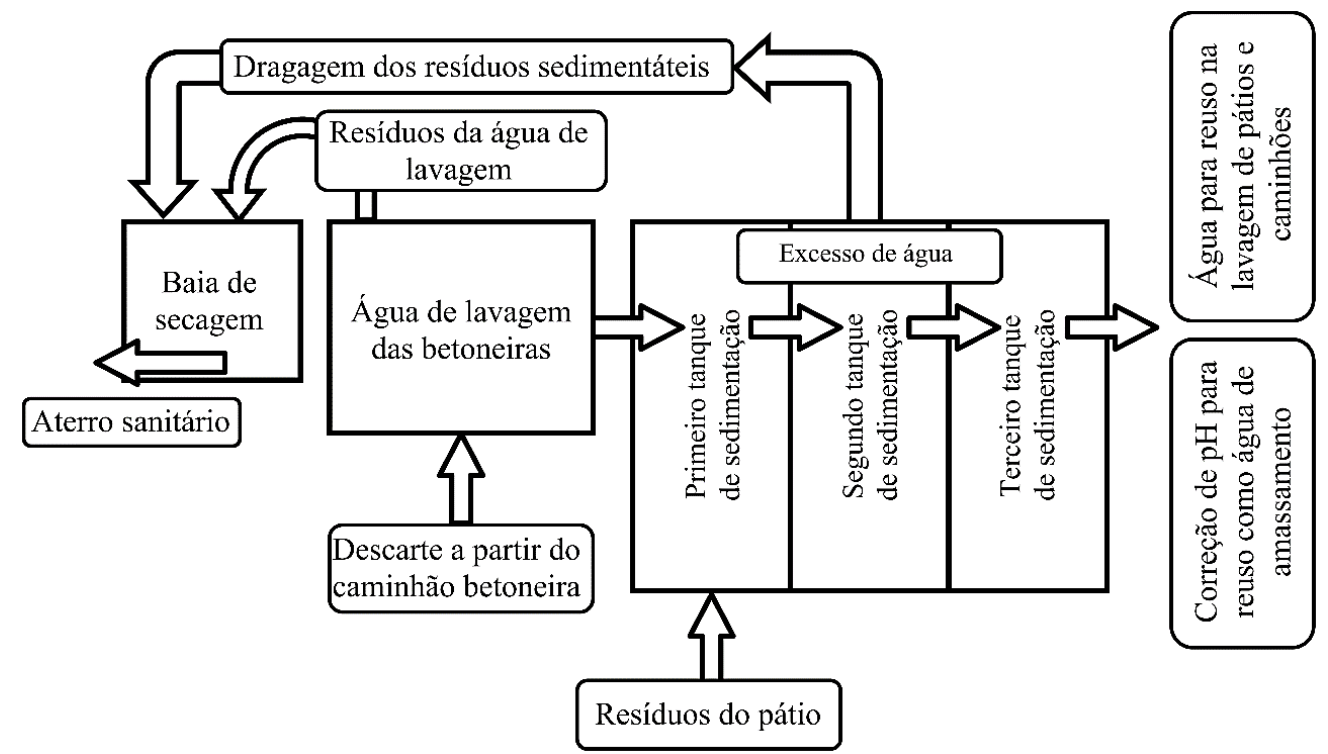

FIGURA 6: Sistema de tratamento da água residuária de usinas de concreto utilizando tanques de sedimentação. FONTE: Adaptado de Sealey; Phillips e Hill (2001).

Ao resíduo sólido sedimentado no fundo do primeiro tanque, composto basicamente por agregado residual do concreto original e pasta de cimento, dá-se o nome de lama residual de concreto (SILVA, 2016). Periodicamente, é necessário que seja realizada a limpeza dos tanques, esvaziando-os e colocando todo o montante sólido a parte, numa baia de secagem. Após tal procedimento, pode-se dispor o resíduo em aterros sanitários (ERMCO, 2006). No entanto, a eliminação e disposição de resíduos sólidos tem se tornado um problema para a sociedade. Nesse contexto, iniciativas como a utilização de resíduos em elementos de concreto podem se apresentar como alternativas viáveis.

O cimento Portland é o componente que agrega maior valor na fabricação de unidades de alvenaria e, portanto, a utilização da lama residual de concreto como seu substituto poderá não só trazer benefícios ambientais, mas também reduzir diretamente os custos de produção. Nesse sentido, a oportunidade que se tem é de transformar esse resíduo cimentício em uma matéria-prima de valor comercial.

\subsubsection{Caracterização da lama residual de concreto}

Algumas características físicas dos materiais constituintes de elementos de concreto são um fator de grande importância para seu desempenho. Nesse sentido, tanto a lama residual de concreto, quanto os demais materiais constituintes, foram analisados por diferentes autores (Tabela 4).

Avaliando os intervalos dos resultados de caracterização encontrados para a lama residual de concreto, pode-se verificar certa variação entre os parâmetros. Isso indica que o resíduo pode variar em função dos materiais incorporados ou das amostras avaliadas, ressaltando a importância da caracterização física para cada estudo. É possível perceber também que, quando comparado com os demais materiais, a lama possui características marcantes, como: baixa densidade e alta absorção de água e, portanto, a sua utilização resultará em concretos menos densos e com uma maior demanda de água na mistura.

As características químicas do cimento Portland Tipo I e da lama residual de concreto, segundo alguns autores, estão apresentadas na Tabela 5. Avaliando especificamente a composição elementar da lama residual, atribui-se a concentração de $\mathrm{CaO}$ e $\mathrm{SiO} 2$ à presença do cimento e de areia fina restantes do concreto original (XUAN et al. 2016b). 
TABELA 4: Características físicas do cimento Portland Tipo Il e da lama residual de concreto segundo alguns autores.

\begin{tabular}{|c|c|c|c|c|c|}
\hline Material & Pesquisadores & $\begin{array}{c}\text { Módulo de } \\
\text { finura }\end{array}$ & $\begin{array}{c}\text { Densidade } \\
\left(\mathrm{g} / \mathrm{cm}^{3}\right)\end{array}$ & $\begin{array}{c}\text { Densidade } \\
\mathrm{SSS}^{*}\left(\mathrm{~g} / \mathrm{cm}^{3}\right)\end{array}$ & $\begin{array}{c}\text { Absorção de } \\
\text { água (\%) }\end{array}$ \\
\hline \multirow{6}{*}{$\begin{array}{l}\text { Lama residual } \\
\text { de concreto }\end{array}$} & Correia et al. (2009) & 1,58 & - & - & - \\
\hline & Kou, Zhan e Poon (2012a) & - & 1,33 & 1,83 & 29,5 e 37,2 \\
\hline & Kou, Zhan e Poon (2012b) & 3,73 & - & 1,83 & 38 \\
\hline & Rughooputh, Rana e Joorawon (2016) & 5,3 & 1,94 & 2,24 & 15,8 \\
\hline & Sérifou et al. (2013) & 3,2 & 2,4 e 2,6 & - & 13 e 4,3 \\
\hline & Audo, Mahieux e Turcry (2016) & - & 2,2 & - & - \\
\hline$C P \| E-32$ & Correia et al. (2009) & 2,9 & 3,02 & - & - \\
\hline Areia natural & Kou, Zhan e Poon (2012a) & 2,11 & 2,59 & 2,63 & 0,89 \\
\hline
\end{tabular}

TABELA 5: Características químicas do cimento Portland Tipo I e da lama residual de concreto segundo alguns autores.

\begin{tabular}{|c|c|c|c|c|}
\hline \multirow[b]{2}{*}{ Frações (\%) } & \multicolumn{3}{|c|}{ Lama residual de concreto } & \multirow{2}{*}{$\frac{\text { CP I }}{\text { Xuan et al. (2016a) }}$} \\
\hline & $\begin{array}{l}\text { Audo, Mahieux e Turcry } \\
\text { (2016)* }\end{array}$ & Schoon et al. (2015) & Xuan et al. (2016a)* & \\
\hline $\mathrm{SiO}_{2}$ & 53,54 & 45,53 & 32,47 & 19,57 \\
\hline $\mathrm{CaO}$ & 34,46 & 25,37 & 35,54 & 64,51 \\
\hline $\mathrm{Al}_{2} \mathrm{O}_{3}$ & 1,92 & 5,66 & 8,34 & 3,81 \\
\hline $\mathrm{Fe}_{2} \mathrm{O}_{3}$ & 1,52 & 1,65 & 6,75 & 3,12 \\
\hline $\mathrm{SO}_{3}$ & 0,77 & 2,03 & 3,12 & 5,43 \\
\hline MgO & - & 3,93 & 1,22 & 1,48 \\
\hline $\mathrm{K}_{2} \mathrm{O}$ & - & 0,54 & 1,55 & 0,69 \\
\hline $\mathrm{TiO}_{2}$ & - & 0,41 & 0,52 & 0,27 \\
\hline $\mathrm{Na}_{2} \mathrm{O}$ & - & 0,26 & - & - \\
\hline $\mathrm{P}_{2} \mathrm{O}_{5}$ & - & 0,17 & - & - \\
\hline $\mathrm{Cl}$ & - & 0,06 & - & - \\
\hline \%LOI** & - & 14 & 10,03 & 5,61 \\
\hline
\end{tabular}

* Resultados médios.

**É a perda de peso após $1050^{\circ} \mathrm{C}$.

4.2.2 Possibilidades de usos da lama residual de concreto ou lama cimentícia na indústria

A leitura dos artigos selecionados permitiu observar que as principais dificuldades apontadas pelos autores para a utilização dessa lama residual em novos produtos foram: a necessidade de um processo específico para obtenção do resíduo e o aumento da demanda de água na mistura para alcançar a mesma trabalhabilidade. Nesse contexto, os autores propuseram diferentes vertentes de estudos, variando desde a função do resíduo na mistura até o tipo de cura do bloco, conforme Figura 7.

Pode-se observar que os resíduos gerados pela indústria de concreto têm sido utilizados de maneiras distintas e por variados autores, conforme
Tabela 6.

No que diz respeito a água residuária, Paula e Ilha (2014) mostram que, com o tratamento de coagulação e correção de $\mathrm{pH}$, esse líquido pode ser reutilizado com qualidade para fins não potáveis como, por exemplo, na lavagem dos caminhões betoneira e do pátio. Já Asadollahfardi et al. (2015) ressaltam que a água residuária pode ser aplicada para a produção de concreto, sem que haja comprometimento considerável das propriedades mecânicas, como trabalhabilidade, resistência à compressão, resistência ao cisalhamento, entre outros.

Com relação aos estudos que utilizaram a lama residual como agregado em concreto propriamente dito, os autores concluíram que 
houve um prejuízo para as propriedades mecânicas do concreto, principalmente a absorção de água. Isso pode ser atribuído ao fato do resíduo ser menos denso e mais fino que o agregado comum (KOU, ZHAN e POON, 2012a) e ao aumento da relação água/cimento $(\mathrm{a} / \mathrm{c})$ para alcançar a mesma trabalhabilidade, contribuindo para o aumento da porosidade total e aumentando assim a absorção de água (CORREIA et al., 2009).

Audo, Mahieux e Turcry (2016) compararam o uso do resíduo seco e fresco como substituto de filer de calcário. Ao final, os autores concluíram que, apesar das duas propostas obterem resistências à compressão equivalentes, a argamassa produzida com a lama residual no estado fresco apresentou maior trabalhabilidade, necessitando assim de menor quantidade de plastificantes e, consequentemente, sendo a opção mais viável. Schoon et al. (2015), por sua vez, trazem uma análise do uso da lama cimentícia como clínquer para o cimento; porém, concluem que o material não está apto para tal função, principalmente por conta da não adequação físicoquímica.

Avaliando especificamente os estudos que utilizaram a lama residual em blocos de concreto, passando pelo processo de secagem e como agregado miúdo, no caso de Kou, Zhan e Poon (2012b) foi verificado que, com o aumento da quantidade de resíduo, há também acréscimo na resistência à compressão. Os referidos autores atribuíram essa elevação de resistência ao efeito filer e à possibilidade de haver cimento ainda não hidratado no resíduo. Já Xuan et al. (2016a, 2016b), além da substituição do resíduo, propuseram também a utilização da carbonatação acelerada com CO2 como método de cura. Em ambos os estudos, os autores verificaram que esta metodologia pode trazer benefícios já nas primeiras horas, melhorando algumas propriedades mecânicas, como a resistência à compressão e a retração por secagem.

É notório que as pesquisas têm abordado o resíduo cimentício em diferentes tipos de usos e funções; no entanto, a utilização da lama residual seca como substituto do aglomerante na produção de blocos de concreto ainda não foi estudada. Tal proposta corrobora com o exposto por Mehta e Monteiro (1994), em que o foco da mistura do concreto deve estar em proporções que minimizem a demanda por cimento, uma vez que tal componente é mais oneroso que os demais constituintes, além de resultar em uma grande liberação de $\mathrm{CO} 2$ para sua produção.

Avaliando as alternativas apresentadas, é possível verificar que ainda não há um consenso quanto à melhor alternativa para a reutilização da lama residual de concreto, ressaltando, assim, a necessidade de novas pesquisas na área.

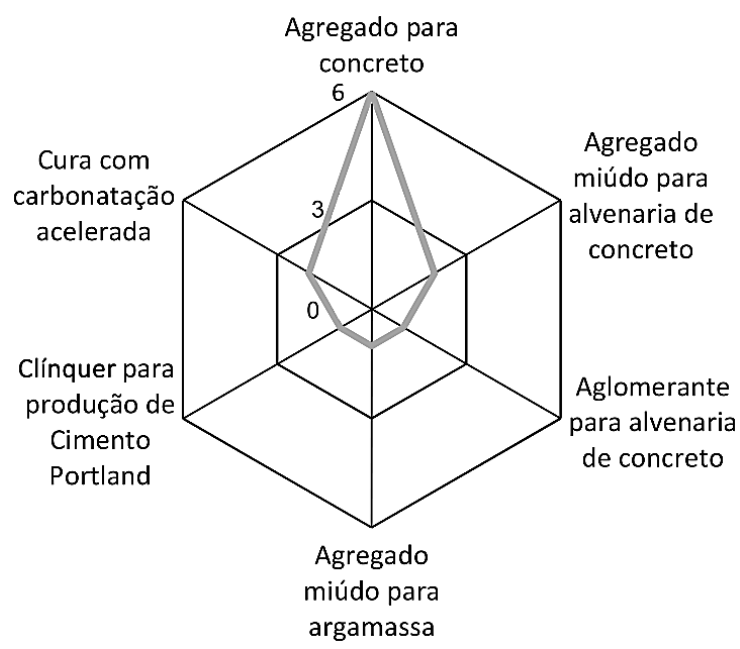

FIGURA 7: Principais funções da lama residual de concreto identificadas nos artigos de periódicos dentro do mapeamento realizado.

FONTE: Autoria Própria. 
TABELA 6: Estudos relacionados com a reciclagem/reutilização da água residuária ou da lama residual de concreto

\begin{tabular}{|c|c|c|c|c|}
\hline Resíduo & Tipo de uso & Função & Estado & Autor \\
\hline \multirow{2}{*}{$\begin{array}{l}\text { Água } \\
\text { residuária }\end{array}$} & Tratamento de água & Reuso & Líquido & Paula e Ilha (2014) \\
\hline & Concreto & Água de amassamento & Líquido & Asadollahfardi et al. (2015) \\
\hline \multirow{8}{*}{$\begin{array}{l}\text { Lama } \\
\text { residual de } \\
\text { concreto }\end{array}$} & Concreto & Agregado graúdo & Seco & Kou, Zhan e Poon (2012a) \\
\hline & Concreto & Agregado miúdo & Seco & Correia et al. (2009) \\
\hline & Concreto & Agregado graúdo e miúdo & Seco & Rughooputh, Rana e Joorawon (2016) \\
\hline & Argamassa & Filer & Seco/Fresco & Audo, Mahieux e Turcry (2016) \\
\hline & Cimento Portland & Clínquer & Seco & Schoon et al. (2015) \\
\hline & Blocos de concreto & Agregado miúdo & Seco & Kou, Zhan e Poon (2012b) \\
\hline & Blocos de concreto & Agregado miúdo & Seco & Xuan et al. (2016b) \\
\hline & Blocos de concreto & Aglomerante & Fresco & Xuan et al. (2016a) \\
\hline
\end{tabular}

\section{CONCLUSÕES}

Através do mapeamento realizado, foi possível verificar que houve uma valorização da gestão ambiental dos resíduos gerados durante a produção de concreto pré-fabricado em usinas dosadoras. Identificou-se também que a lama residual de concreto ou lama cimentícia é um dos principais resíduos desse processo produtivo. Sendo assim, há uma lacuna no desenvolvimento de novos estudos que viabilizem a reciclagem desse resíduo como, por exemplo, substituindo o cimento Portland na produção de blocos de concreto.

A reintegração da lama residual no processo produtivo de um bem durável poderá não só reduzir o volume de resíduos sólidos gerados, mas também a demanda por cimento Portland, modificando diretamente a quantidade de recursos minerais e energéticos consumidos para a produção dessa matéria prima. Para verificar a viabilidade desta proposta, torna-se necessário identificar o comportamento mecânico dos blocos de concreto em função da variação da percentagem de substituição.

Por fim, é necessário destacar que o Mapeamento Sistêmico para a revisão de literatura fornece uma visão mais ampla do campo da pesquisa. Tal panorama permite, além da contemplação do que já está em foco pelos autores, uma melhor definição de áreas que ainda precisam ser desenvolvidas. Vale ressaltar que, com esse método, há ainda a possibilidade de estar em contato com as principais publicações e estudos referentes a vertente desejada.

\section{AGRADECIMENTOS}

Os autores desejam agradecer o apoio concedido pela Universidade Federal de Goiás/ Regional Catalão e pela Fundação de Amparo à Pesquisa do Estado de Goiás - FAPEG. Também agradecemos as Empresas Brasmix Engenharia de Concretos S/A e G S Artes Pré-moldados, pelo fornecimento de materiais e mão de obra necessárias.

\section{REFERÊNCIAS BIBLIOGRÁFICAS}

ALMEIDA, N.; BRANCO, F.; SANTOS, J. R. Recycling of stone slurry in industrial activities: Application to concrete mixtures. Building And Environment, [s.I.], v. 42, n. 2, p.810-819, fev. 2007. Elsevier BV.

ASADOLLAHFARDI, G. et al. Experimental and statistical studies of using wash water from ready-mix concrete trucks and a batching plant in the production of fresh concrete. Construction and Building Materials, [s.l.], v. 98, p.305-314, nov. 2015. Elsevier BV.

ASSOCIAÇÃO BRASILEIRA DE CIMENTO PORTLAND. Pesquisa inédita e exclusiva revela cenário do mercado brasileiro de concreto. São Paulo, 2013. Disponível em: <http://www.abcp.org.br/>. Acesso em jan 2016.

ASSOCIAÇÃO BRASILEIRA DE NORMAS TÉCNICAS. NBR 12653: Materiais pozolânicos - Requisitos. Rio de Janeiro, 2014. 6p. 
AUDO, M.; MAHIEUX, P.; TURCRY, P.. Utilization of sludge from ready-mixed concrete plants as a substitute for limestone fillers. Construction And Building Materials, [s.I.], v. 112, p.790-799, jun. 2016. Elsevier BV.

BAILEY, J. et al. Evidence relating to Object-Oriented software design: A survey. First International Symposium On Empirical Software Engineering And Measurement (esem 2007), [s.I.], p.482-484, set. 2007. Institute of Electrical and Electronics Engineers (IEEE).

CORREIA, S.I. et al. Assessment of the recycling potential of fresh concrete waste using a factorial design of experiments. Waste Management, [s.I.], v. 29, n. 11, p.2886-2891, nov. 2009. Elsevier BV.

ERMCO - European Ready Mixed Concrete Organization. Guidance on Concrete Wash Water in the European Ready Mixed Concrete Industry. Bélgica: 2006. Disponível em

http://www.ermco.eu/document/ermco_wash_water_g uidance_oct_2006-pdf/>. Acesso em jan 2016.

KOU, S.; ZHAN, B.; POON, C.. Feasibility study of using recycled fresh concrete waste as coarse aggregates in concrete. Construction And Building Materials, [s.l.], v. 28, n. 1, p.549-556, mar. 2012a. Elsevier BV.

KOU, S.; ZHAN, B.; POON, C.. Properties of partition wall blocks prepared with fresh concrete wastes. Construction And Building Materials, [s.I.], v. 36, p.566-571, nov. 2012b. Elsevier BV.

MEHTA, P. K., MONTEIRO, P. J. M. - Concreto: estrutura, propriedade e materiais. São Paulo: Pini, 1994. 573p.

PAULA, H. M. de; ILHA, M. S. O. USO DA MORINGA OLEIFERA NO TRATAMENTO DE ÁGUAS REDISUÁRIAS DE USINAS DE CONCRETO: MAPEAMENTO SISTEMÁTICO (doi. Reec - Revista Eletrônica de Engenharia Civil, [s.I.], v. 11, n. 1, p.50-60, 1 fev. 2016. Universidade Federal de Goiás.

PAULA, H. M.; ILHA, M. S. O.. Quality of concrete plant wastewater for reuse. Revista Ibracon de Estruturas e Materiais, [s.I.], v. 7, n. 3, p.349-366, jun. 2014. FapUNIFESP (SciELO).

PETERSEN, K.; FELDT; R.; MUJTABA, S.; MATTSSON, M. Systematic Mapping Studies in Software Engineering. School of Engineering, Blekinge Institute of Technology. University of Bari, Italy, 26 - 27 June. 2008.

RUGHOOPUTH, R.; RANA, J. O.; JOORAWON, K.. Possibility of using fresh concrete waste in concrete for non structural civil engineering works as a waste management strategy. Ksce Journal of Civil Engineering, [s.I.], v. 21, n. 1, p.94-99, 28 mar. 2016. Springer Nature.
SCHOON, J. et al. Feasibility Study of the Use of Concrete Sludge As Alternative Raw Material for Portland Clinker Production. Journal of Materials In Civil Engineering, [s.I.], v. 27, n. 10, p.1-12, out. 2015. American Society of Civil Engineers (ASCE).

SEALEY, B.j.; PHILLIPS, P.s.; HILL, G.j.. Waste management issues for the UK ready-mixed concrete industry. Resources, Conservation And Recycling, [s.I.], v. 32, n. 3-4, p.321-331, jul. 2001. Elsevier BV.

SÉRIFOU, M. et al. A Study of Concrete Made with Fine and Coarse Aggregates Recycled from Fresh Concrete Waste. Journal of Construction Engineering, [s.l.], v. 2013, p.1-5, 2013. Hindawi Publishing Corporation.

SILVA, D. O. F. Reaproveitamento de lamas residuais do processo de fabricação do concreto. Tese (Mestrado em Ciências) - Escola Politécnica da Universidade de São Paulo, São Paulo, 2016

TAM, Vivian W.y.. Economic comparison of concrete recycling: A case study approach. Resources, Conservation And Recycling, [s.I.], v. 52, n. 5, p.821-828, mar. 2008. Elsevier BV.

TSIMAS, S.; ZERVAKI, M.. Reuse of waste water from ready-mixed concrete plants. Management of Environmental Quality: An International Journal, [s.l.], v. 22, n. 1, p.7-17, 4 jan. 2011. Emerald.

VIEIRA, L. B. P., Figueiredo, A. D., Resíduos da Concreteira: o aproveitamento do problema. Revista Concreto IBRACON, [s.I.] v. 22, n.71, p.49-53, 2013.

XUAN, D. et al. Carbon dioxide sequestration of concrete slurry waste and its valorisation in construction products. Construction And Building Materials, [s.I.], v. 113, p.664-672, jun. 2016b. Elsevier BV. http://dx.doi.org/10.1016/j.conbuildmat.2016.03.109.

XUAN, D. et al. Innovative reuse of concrete slurry waste from ready-mixed concrete plants in construction products. Journal of Hazardous Materials, [s.I.], v. 312, p.65-72, jul. 2016a. Elsevier BV. 